\title{
Perspective, Voice, Reference, and Warrant: A Sample of Ameliorations to the Multi-Perspective Design Requirement and Some Arguments Against It
}

\author{
Joseph T. Tennis \\ University of Washington iSchool \\ jtennis@uw.edu
}

\section{INTRODUCTION}

When one thinks of multi-perspective classification, a number of structural ameliorations mentioned in the literature come to mind. It is possible that the phase relations outlined by S. R. Ranganathan (1953; 1965; 1967), or the forms of thought outlined by Langridge (1989) could serve to express more than one perspective. Further, there are a number of factors that figure into the communication of single or multiple perspectives in classification schemes. For example, there are semantic, syntactic, and pragmatic factors that can shape how perspective is communicated in classification schemes. One can observe that the extension and intension of a class (semantics) may shift over time or between contexts, such that a term like totem could communicate a wide range of meanings. Further, the structure (or syntax) of the classification scheme (either hierarchical or polyhierarchical) and the order of the classes as a group (pragmatics of classification) manifest particular perspectives.

In this concept paper I sketch these potential ameliorations at a high level and then work to address some foundational issues associated with attempts at communicating multiple perspectives in a single classification scheme. These include both Melanie Feinberg's work on rhetorical stance of the classificationist $(2010,2012)$ and Birger Hjørland's work on explicit philosophical grounding and classification scheme design (2013).

I close with summing up some of the mechanisms that serve to ground an argument that a classification scheme can be multi-perspective. I have called this section, and this paper, after the four mechanisms I see at this time: perspective, voice, reference, and warrant.

\section{Ranganathan's Phase Relations}

With the advent of faceted classification, in the context of S. R. Ranganathan's theory of classification, there also arose the need to accommodate subject description from multiple viewpoints. However, the original phase relations were not as expansive as what might be needed in the contemporary environment and the call for consideration of this workshop.

\begin{tabular}{|c|c|}
\hline 1953 & 1967 \\
\hline $\begin{array}{l}\text { Bias (Economics for } \\
\text { Mathematicians) }\end{array}$ & $\begin{array}{l}\text { Bias (statistical } \\
\text { analysis for railway } \\
\text { engineering) }\end{array}$ \\
\hline \multicolumn{2}{|l|}{$\begin{array}{l}\text { Tool (Mathematical } \\
\text { economics) }\end{array}$} \\
\hline $\begin{array}{l}\text { Influence (Influence } \\
\text { of mathematics on } \\
\text { economics) }\end{array}$ & $\begin{array}{l}\text { Influencing } \\
\text { (Influence of } \\
\text { geography on history) }\end{array}$ \\
\hline $\begin{array}{l}\text { Comparison } \\
\text { (Economics and } \\
\text { mathematics } \\
\text { compared) }\end{array}$ & $\begin{array}{l}\text { Comparison (example } \\
\text { not given) } \\
\text { (biochemistry } \\
\text { compared with } \\
\text { physiology - 1965) }\end{array}$ \\
\hline \multirow[t]{2}{*}{$\begin{array}{l}\text { General Relation } \\
\text { (Relation of } \\
\text { economics with } \\
\text { mathematics) }\end{array}$} & $\begin{array}{l}\text { General (General } \\
\text { relation between } \\
\text { political science and } \\
\text { economics) }\end{array}$ \\
\hline & $\begin{array}{l}\text { Difference } \\
\text { (Difference between } \\
\text { Lemuroidea and } \\
\text { Anthropodoidea) }\end{array}$ \\
\hline
\end{tabular}

It is easy to see from these figures, that were we creative, we could come up with other phase relations based on critiques of single-perspective classification in the literature.

\section{Langridge's Forms of Thought}

In his 1989 work, Langridge outlines improvements to classification scheme design by identifying how we might break down subjects into particular categories of semantics. His five broad categories are: forms of knowledge, topics, specializations, forms of thought, and forms of text.

1. Form of Knowledge: like Philosophy, Natural Science, Criticism, etc.

2. Topics: like "the mind", to things particular like "descriptors in the MLA bibliography".

3. Specializations: Intersection between topics and forms of knowledge 
Forms of Writing: Formal Characteristics of two types: form of thought and form of text

4. Form of Thought:

4.1. Viewpoint

Overarching set of presuppositions? / Worldviews [e.g., Marxism, Christian view points]

Philosophical viewpoints [e.g., rationalism, empiricism, pragmatism, realism, idealism, humanism, and agnosticism] Schools of thought

Personal point of view

Instructive

(description, analysis, interpretation, narrative, prescription, prediction and evaluation)

Persuasive (e.g., sermon, speech, legal pleading)

Imaginative (genre, sub-genre, and mode)

4.2. Method

4.3. Intellectual Level (beginner and advanced)

4.4. Primary documents

4.5. Secondary documents (textbooks, popularizations, works describing procedures, works

describing methods, techniques)

4.6. Audience (for nurses, for engineers)

5. Form of the text:

5.1. Medium of communication (English, French, Russian, translation from one to the other, mathematical symbols, pictoral)

5.2. Structure of the text (i.e., bibliographic forms like monograph, dissertation, reference work, etc.)

In the context of the forms of thought, we see viewpoint called out as having the potential to express many points of view. This could be a seed list for phase relations combining both Ranganathan and Langridge.

\section{Meaning in Linguistics and Its Relationship to Classification Theory: Semantics, Syntax, and Pragmatics}

Perspective may have something to do with a pragmatics of a classification scheme, that is how a classificationist outlines the order of classes. What is considered primary may come first, what is ancillary may come last. This order is generally fixed, but classification schemes have offered suggestions for variation (e.g., Cutter's Expansive Classification). The semantics, however, is quite challenging. The extension and intension of a class is often underspecified and relies on context and comparison (and application to particular collections often). So the meaning represented is always of a perspective, but it is not always easy to discern what perspective it is and how it might be changed. The example, given above, of totem relies on context - the syntax and pragmatics of the classification scheme to carry meaning.

Feinberg's Rhetorical Stances of the Classificationist If a classificationist is arguing for their perspective, and perhaps it is a perspective open to multiple perspectives, we must contemplate what a rhetorical stance to classification gives us. If we follow Feinberg, namely that we have an opportunity to act intentionally in the design of classification schemes and in so doing present a single argument for one way of representing the world, we are then denied the ability to make clear multiple perspectives. We would have to somehow extend Feinberg's design method to accommodate some kind of polyphony. This is a move beyond phase relations and would require a level of sophistication that most classification schemes currently lack.

\section{Hjørland and Philosophical Grounding}

Though there are significant differences between Feinberg and Hjørland, they are both arguing for explicit stances in a way. Hjørland, by contrast to Feinberg, claims that an explicit philosophical stance must be articulated by the classificationist. If this stance were, by its nature, open to representing multiple perspectives, then it seems we might, in a sophisticated structure, do that kind of representation. But, not unlike the Feinberg case, we would need more than we have currently as regards representation power.

\section{Perspective, Voice, Reference, and Warrant}

When we think substantially about how classification theorists have thought about multi-perspective classification, we can ground their ameliorations into at least four kinds: perspective, voice, reference, and warrant. Perhaps these can be used to build out design requirements in a more sophisticated incarnation of classification.

\section{Perspective is Relational}

In all the definitions of perspective we see it is a concept that is composed relationships. It is the subject's relationship to an object. This can be a physical, visual, or rhetorical relationship. This is concretely what an extension of Ranganathan's phase relations would be, as well as Langridge's forms of thought.

\section{Voice is Unmarked}

Multi-perspective classification could also be one that was not univocal but represents many voices. The marking of whose voice is speaking and where it appears in the scheme is required, and yet this seems difficult to represent in our current structures.

\section{Reference is External and Internal}

For us to see multiple perspectives we need those perspectives contextualized. They need to make reference to something, either internally or external to the scheme. With most classes underspecified the work of reference is to fix a single meaning to a class. This would need to be overcome in a multi-perspective scheme.

\section{Warrant is Perhaps Singular}

Finally, warrant shapes perspectives. The choice of warrant, how it is mentioned in the descriptive material of 
the scheme and how to use it, and the decision to privilege some concepts over other even in the context of a welldocumented warrant works against the representation of multiple perspectives. Again, we will require more sophisticated structures and paratextual elements in order to overcome this challenge.

\section{CONCLUSION}

While on the surface the representation of multiple perspectives in a single classification scheme might be accommodated by phase relationships and calling out viewpoints in the process of subject analysis, there are competing design requirements that seek to discipline the classification to a single perspective. The other challenge is in the poverty of the current representation systems.

Perhaps by explicitly outlining these issues, we can craft new design requirements and innovate in our structural representation of subjects to accommodate multiple perspectives.

\section{REFERENCES}

Feinberg, M. (2010). Two kinds of evidence: how information systems form rhetorical arguments. In Journal of Documentation 66(4): 491-512.

Feinberg, M. (2012). Compiler to Author: A Process for Designing Rhetorically Aware Document Collections. In Journal of the American Society for Information Science and Technology 62(9): 1784-1796.

Hjørland, B. (2013). Theories of knowledge organization - theories of knowledge: Keynote March 19, 2013. 13th Meeting of the German ISKO in Potsdam. Knowledge Organization, 40(3), 169-181.

Langridge, D. W. 1989, Subject Analysis: Principles and Procedures, Bowker-Saur.

Ranganathan, S. R. (1953). Depth Classification and Reference Service and Reference Material. Indian Library Association English Series \#6. Indian Library Association: Delhi.

Ranganathan, S. R. (1963). Documentation and its Facets: Being a Symposium of Seventy Papers by Thirty-two Authors. Sarada Ranganathan Endowment for Library Science Series \#10. Asia Publishing House.

Ranganathan, S. R. (1967). Prolegomena to Library Classification. 3rd Ed. Asia Publishing House: Bombay. 